\title{
Luminous and solar characterization of PV modules for building integration
}

\author{
F.J. Moralejo-Vázquez , N. Martín-Chivelet ，L. Olivieri ， E. Caamaño-Martín
}

Keywords:

Building integrated photovoltaics

BIPV

Optical characterization

PV module

PV laminate

PV glazing

Spectrophotometry

Transparency

\begin{abstract}
A B S T R A C T
The optical characterization of different PV modules for integration in buildings (BIPV) is presented in this paper. The investigated PV modules are laminated glasses (PV laminates) suitable for integration in façades and windows. They are made of different PV cell technologies and some of them present a certain transparency degree, making possible to combine daylighting properties with solar control and electrical generation. The approach is based on spectral UV/vis/NIR reflectance and transmittance measurements of the different considered samples, both at normal incidence and as a function of the angle of incidence when it is possible. The European standard protocols are used to determine the luminous and the solar characteristics of each sample, enabling the optical assessment of these PV modules as building elements. The results indicate the good properties of PV laminates in terms of daylighting and solar control capabilities allowing a feasible efficient integration in building façades and windows. The obtained characteristic parameters can be used to simulate the influence in the energy balance of a building of different types of PV modules integrated in façade or window elements.
\end{abstract}

\section{Introduction}

The integration of photovoltaic (PV) technology in buildings makes the PV modules become construction elements of the envelope. This activity, commonly named as Building Integrated Photovoltaics (BIPV), combines the architectural integration of the PV modules with renewable electricity generation in buildings. The optimization of these elements from the electrical, thermal and optical points of view will improve the building energy efficiency [1]. According to the current European regulations about the energy performance of buildings and energy efficiency, such as Directives 2010/31/EU, and 2012/27/EU, respectively [2,3], the energy performance of buildings should be calculated on the basis of a methodology which consider thermal characteristics, adequate natural lighting, heating and air-conditioning installations, application of energy from renewable sources, passive heating and cooling elements, shading, indoor air-quality, and design of the building.
Furthermore, the methodology should take into account existing norms, such as ISO 9050:2003 [4], EN 410:2011 [5] and NFRC ${ }^{1}$ $300: 2014$ [6] for glass in building, which specify some methods of determining the luminous and solar characteristics of glazing in buildings that serve as a base for lighting, heating and cooling calculations of rooms and permit the comparison between different types of glazing elements. These methods can be applied to a wide range of glazing systems, including PV modules designed to be integrated into façades. Nevertheless, they don't include aspects such as the angle dependence of the laminate properties or the behavior of the active glazings (photovoltaic, electrochromic ...), aspects to be considered for a more accurate knowledge of their real operation.

In this study the main features that should be included in the optical characterization of PV modules for building integration, as façade laminated glasses, have been considered. The measurements have been performed on different PV samples with a laminated glass structure. Spectral reflectance and transmittance properties $R(\lambda, \alpha), T(\lambda, \alpha)$, in the ultraviolet, visible and near infrared (UV/vis/NIR) ranges were measured, both at perpendicular incidence and as a function of the angle of incidence, to assess the

\footnotetext{
1 The National Fenestration Rating Council (NFRC) is a United States non-profit organization which develops and operates tests methods for energy-related performance of fenestration products.
} 


\begin{tabular}{|c|c|}
\hline \multicolumn{2}{|c|}{ Nomenclature } \\
\hline$\alpha$ & angle of incidence \\
\hline$\alpha_{e}$ & solar direct absorptance \\
\hline$\rho_{e}$ & solar direct reflectance \\
\hline$\rho_{V}$ & light reflectance \\
\hline$\rho_{V, \text { Rear }}^{\# \#}$ & $\begin{array}{l}\text { backside light reflectance under the \#\# standard } \\
\text { illuminant }\end{array}$ \\
\hline$\tau_{e}$ & solar direct transmittance \\
\hline$\tau_{\mathrm{UV}}$ & ultraviolet transmittance \\
\hline$\tau_{V}$ & light transmittance \\
\hline AM $1.0 \mathrm{G}$ & global standard spectra for 1.0 air mass \\
\hline D65 & CIE standard illuminant D65 (daylight) \\
\hline$D_{\lambda}^{\# \#}$ & $\begin{array}{l}\text { relative spectral distribution of the \#\# standard illu- } \\
\text { minant }\end{array}$ \\
\hline$D f R$ & normal diffuse reflectance \\
\hline DfT & normal diffuse transmittance \\
\hline$D R$ & normal directional reflectance \\
\hline \multicolumn{2}{|c|}{$D R\left(\# \#^{\circ}\right)$ directional reflectance at \#\# an } \\
\hline DT & normal directional transmittance \\
\hline \multicolumn{2}{|c|}{ DT $\left(\# \#^{\circ}\right)$ directional transmittance at \#\# angle } \\
\hline F2 & CIE standard illuminant F2 (fluorescent lamp) \\
\hline$g$ & solar factor \\
\hline$H R$ & normal hemispherical reflectance \\
\hline$H T$ & normal hemispherical transmittance \\
\hline$h_{e}$ & external heat transfer coefficient \\
\hline$h_{i}$ & internal heat transfer coefficient \\
\hline$q_{i}$ & secondary internal heat transfer factor \\
\hline$R(\lambda, \alpha)$ & spectral reflectance \\
\hline$R_{a}$ & general color rendering index \\
\hline$S_{\lambda}$ & $\begin{array}{l}\text { relative spectral distribution of standard solar radi- } \\
\text { ation AM } 1.0 \mathrm{G}\end{array}$ \\
\hline$S$ & selectivity \\
\hline SC & shading coefficient \\
\hline$T(\lambda, \alpha)$ & spectral transmittance \\
\hline$U_{\lambda}$ & $\begin{array}{l}\text { relative spectral distribution of standard UV solar } \\
\text { radiation }\end{array}$ \\
\hline$\left(U^{*}, V^{*}, 1\right.$ & $W^{*}$ ) CIE 1964 uniform color space coordinates \\
\hline$V(\lambda)$ & $\begin{array}{l}\text { spectral luminous efficiency of the standard pho- } \\
\text { topic observer }\end{array}$ \\
\hline
\end{tabular}

derived properties of the PV laminates also in orientations closer to those more common in real façades. The results have allowed the characterization and analysis of the luminous and solar behavior of the PV laminates, showing that these elements can be efficiently integrated in building façades.

\section{Technical approach}

\subsection{Description of the samples}

The samples considered are PV modules and equivalent technology PV solar cells (ETSCs) ${ }^{2}$ supplied by different manufacturers, appropriately representative of PV modules suitable for building integration as façade elements $[7,8]$. As mentioned in the introduction, all of them have a laminated glass structure, resulting nine of them semi-transparent and three opaque. The considered samples cover the main current PV technologies.

Five of the semi-transparent samples are based on crystalline silicon technologies - Edge-Defined Film-Fed Growth silicon (EFG)

\footnotetext{
2 Encapsulated PV solar cells with the same technology and laminated structure as the PV module.
}

and multicrystalline silicon (mc-Si) - and the other four are based on amorphous silicon. More in detail: one PV module with EFG silicon PV solar cells encapsulated with resin (EFGSi); two similar commercial PV modules with mc-Si PV solar cells and polivinil butyral (PVB) as encapsulant, the first one (mcSi_a) new and the second one (mcSi_b) degraded after years of use, showing an aged yellowed encapsulant; a multicrystalline silicon ETSC encapsulated with PVB ( $\left.m c S i_{-} c\right)$, another multicrystalline silicon ETSC (mcSi_d), which is semitransparent due to a laser-perforated structure and is encapsulated with ethylene vinyl acetate (EVA), and four commercial semi-transparent PV modules based on amorphous silicon (a-Si) with different degrees of transparency: 10\%, 20\%, 30\% and 40\% (aSi_a-\#, with '\#' being 10, 20, 30 and 40, respectively).

The degree of transparency of these semitransparent samples is achieved either by leaving regularly distributed transparent gaps between the PV cells, which is the case in crystalline silicon samples (EFGSi, mcSi_a, mcSi_b, mcSi_c), and/or removing part of the solar cells' active material, which is the case in the amorphous silicon samples (aSi_a-\#) and in one of crystalline silicon (mcSi_d). The different types of regions (transparent, opaque) are characterized separately when possible. In these cases, the overall luminous and solar properties are constructed by weighting the obtained ones in the transparent and opaque regions by their correspondent percentage of area. In the rest of the cases the properties correspond to areas intercepting both types of regions.

In the particular case of amorphous silicon, PV laminates with the same structure as PV modules have been cropped from commercial modules at a smaller size for testing convenience, allowing the measurement of angular reflectance and transmittance of these laminates.

The three opaque samples are based on different commercial technologies: amorphous silicon (aSi_b), cadmium telluride (CdTe) and cupper indium selenide (CIS).

Pictures and details of each sample are included in Fig. 1 and Table 1 , respectively.

The higher transparency degrees reduce their electrical efficiency values when compared to conventional PV modules. This reduction is roughly proportional to the transparency increase. Typical efficiency values of regular PV modules are $15 \%$ if monocrystalline silicon, $6 \%$ if single-junction amorphous silicon, and $12 \%$ if cadmium telluride or cupper indium selenide.

\subsection{Experimental setup}

The measurements taken are the following:

- Hemispherical $(H)$ and diffuse (Df) spectral reflectance $(R)$ and transmittance $(T)$ at normal angle of incidence, denoted as $H R$, $D f R, H T$, and $D f T$.

- Directional $(D)$ spectral reflectance and transmittance at normal incidence and at different angles of incidence, denoted, respectively, as $D R\left(\# \#^{\circ}\right)$ and $D T\left(\# \#^{\circ}\right)$.

These spectral properties have been measured both from the frontal PV active side and from the backside.

Spectral reflectance and transmittance measurements have been made with a Perkin Elmer ${ }^{\circledR}$ Lambda 900 UV/vis/NIR spectrophotometer [9] equipped with a LabSphere ${ }^{\circledR} 150 \mathrm{~mm}$ integrating sphere Spectralon ${ }^{\circledR}$ coated [10]. The integrating sphere provides a bigger effective collection surface for the detectors, equivalent to the sphere input ports area $(1 \mathrm{in} . / 25.4 \mathrm{~mm})$. For the angle dependent directional $R / T$ measurements, a Directional Reflectance/Transmittance set, from TNO Institute of Applied Physics, has been used [11] (Fig. 2). The wavelength accuracy of the instrument is $\pm 0.08 \mathrm{~nm}$ (UV/vis) and $\pm 0.32 \mathrm{~nm}$ (NIR). The photometric accuracy of the instrument is transmission $\pm 0.08 \%$ at 

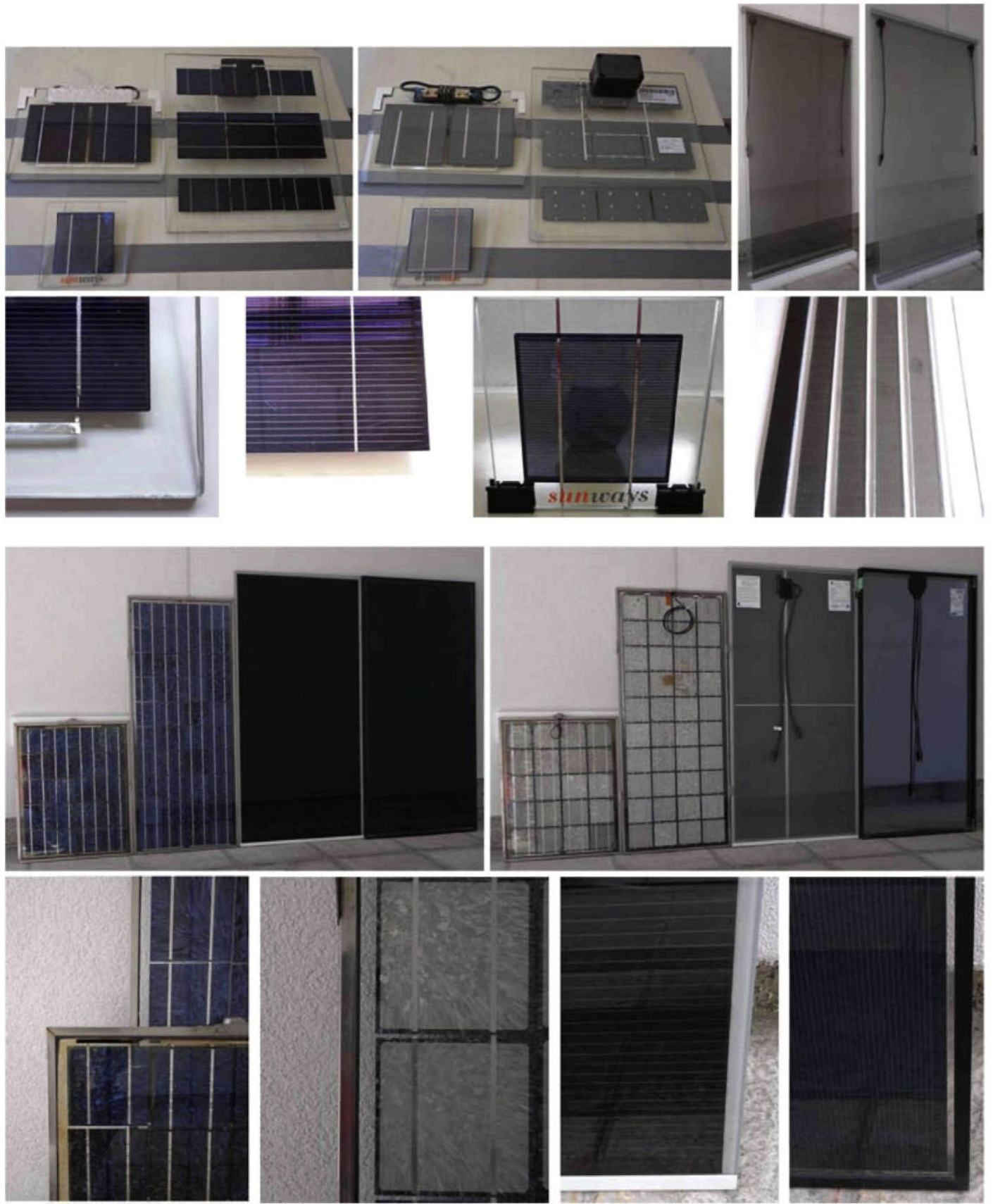

Fig. 1. Front and back pictures of the considered ETSCs and PV modules.
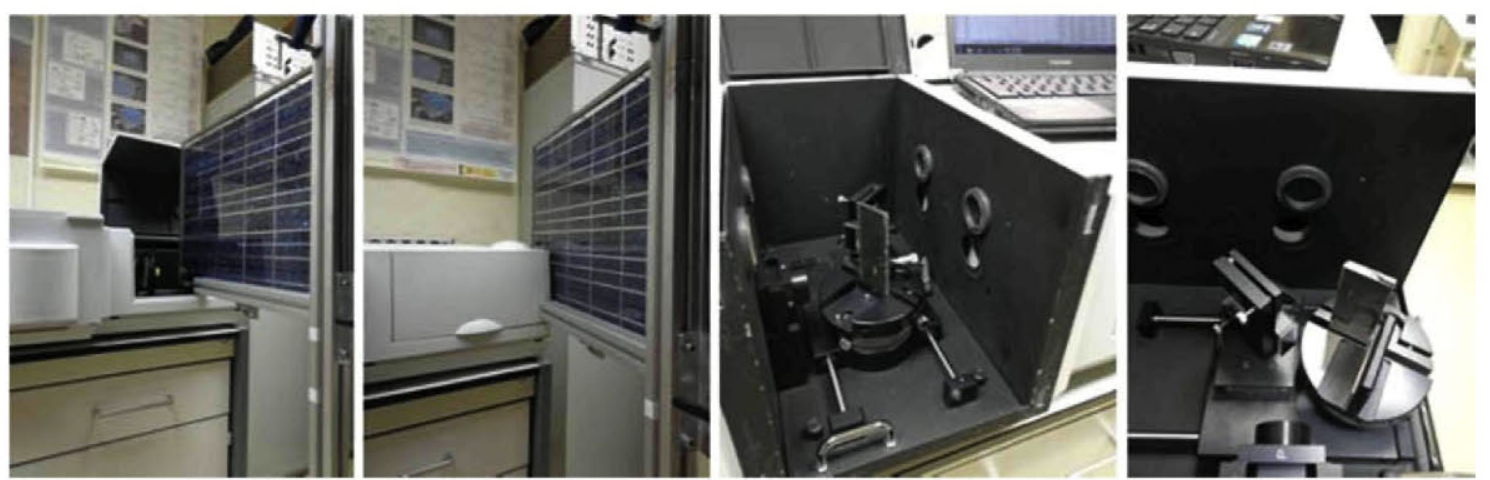

Fig. 2. Spectrophotometer Perkin Elmer ${ }^{\circledast}$ Lambda 900 equipped with the LabSphere ${ }^{\circledast} 150 \mathrm{~mm}$ integrating sphere for testing the spectral transmittance and reflectance of PV modules, and with the TNO Directional $R / T$ set for the directional and angular characterization of the smaller samples. 
Table 1

Description of the considered PV modules and ETCs.

\begin{tabular}{|c|c|c|c|c|c|c|c|c|c|}
\hline \multirow{2}{*}{$\begin{array}{l}\text { Technology } \\
\text { Name }^{\mathrm{a}}\end{array}$} & \multicolumn{5}{|c|}{ Crystalline silicon PV solar cells } & \multicolumn{4}{|c|}{ Thin film PV solar cells } \\
\hline & EFGSi & $m c S i \_a$ & $m c S i b$ & mcSi_c & $m c S i \_d$ & $\begin{array}{l}\text { aSi_a-(4 } \\
\text { samples) }\end{array}$ & $a S i b$ & CdTe & CIS \\
\hline System type & PV module & PV module & $\begin{array}{l}\text { PV module } \\
\text { (aged) }\end{array}$ & ETSC & ETSC & PV module & PV module & PV module & PV module \\
\hline Frontal glass & $\begin{array}{l}3.2 \mathrm{~mm} \text { low } \\
\text { iron }\end{array}$ & Low iron & Low iron & $\begin{array}{l}4.0 \mathrm{~mm} \text { low } \\
\text { iron }\end{array}$ & $\begin{array}{l}3.0 \mathrm{~m} \text { low } \\
\text { iron }\end{array}$ & $\begin{array}{l}3.2 \mathrm{~mm} \\
\text { textured }\end{array}$ & $\begin{array}{l}3.2 \mathrm{~mm} \\
\text { textured }\end{array}$ & $\begin{array}{l}3.2 \mathrm{~mm} \\
\text { heat }\end{array}$ & $\begin{array}{l}3.0 \mathrm{~mm} \text { low } \\
\text { iron }\end{array}$ \\
\hline $\begin{array}{l}\text { Frontal } \\
\text { encapsulant }\end{array}$ & Resin & PVB foil & PVB foil & PVB foil & EVA foil & $\begin{array}{l}\text { float with } \\
\text { TCO }\end{array}$ & $\begin{array}{l}\text { float with } \\
\text { TCO }\end{array}$ & $\begin{array}{l}\text { strength- } \\
\text { ened. with } \\
\text { TCO }\end{array}$ & EVA foil \\
\hline PV cell technology & EFG-Si & $\mathrm{mc}-\mathrm{Si}$ & $\mathrm{mc}-\mathrm{Si}$ & $\mathrm{mc}-\mathrm{Si}$ & $\mathrm{mc}-\mathrm{Si}$ & $\begin{array}{l}\text { a-Si/a-Si } \\
\text { tándem }\end{array}$ & $\begin{array}{l}\text { a-Si/a-Si } \\
\text { tandem }\end{array}$ & $\mathrm{CdTe}$ & CIS \\
\hline Back-contact & Al & $\begin{array}{l}\mathrm{Ag} \\
\text { (evaporated) }\end{array}$ & $\begin{array}{l}\mathrm{Ag} \\
\text { (evaporated) }\end{array}$ & $\mathrm{Al}$ & $\mathrm{Al}$ & $\mathrm{Al}$ & Al & $\mathrm{Ni}-\mathrm{Al}$ & Mo \\
\hline Rear encapsulant & Resin & PVB foil & PVB foil & PVB foil & EVA foil & $\begin{array}{l}0.45 \mathrm{~mm} \text { EVA } \\
\text { foil }\end{array}$ & $\begin{array}{l}0.45 \mathrm{~mm} \text { EVA } \\
\text { foil }\end{array}$ & EVA foil & $\begin{array}{l}3.0 \mathrm{~mm} \\
\text { soda-lime }\end{array}$ \\
\hline Rear glass & $\begin{array}{l}3.2 \mathrm{~mm} \text { low } \\
\text { iron } \\
\text { tempered }\end{array}$ & tempered & tempered & $\begin{array}{l}4.0 \mathrm{~mm} \\
\text { tempered }\end{array}$ & $\begin{array}{l}4.0 \mathrm{~mm} \text { low } \\
\text { iron } \\
\text { tempered }\end{array}$ & $3.2 \mathrm{~mm}$ float & $3.2 \mathrm{~mm}$ float & $\begin{array}{l}3.2 \mathrm{~mm} \\
\text { tempered }\end{array}$ & silica \\
\hline Transparency & \multicolumn{5}{|c|}{ Semi-transparent } & & \multicolumn{3}{|l|}{ Opaque } \\
\hline
\end{tabular}

a The nominal transparency of the PV element will be appended to the name, i.e. EFGSi-20, when necessary.

absorbance equal to 1 and transmission $\pm 0.05 \%$ at absorbance equal to 0.5 (measured with NIST (NBS) 930 filters) [12]. The angular accuracy of the $R / T$ device is less than $0.08^{\circ}[11]$.

Transmittance and reflectance were measured from $250-2500 \mathrm{~nm}$ for a $5 \mathrm{~nm}$ intervaland the angular ranges considered for measurements at oblique incidence were $0-75^{\circ}$ in transmittance and $32-72^{\circ}$ in reflectance.

In order to reduce the uncertainty in the measurements as possible, every hemispheric or diffuse property of each sample $u$ has been obtained by averaging over a sequence of measurements at horizontal and vertical positions $(h, v)$ and at two representative regions of the samples $(a, b)$, and correcting by the reference measurements (Ref):

$P_{h, a}^{u} ; P_{v, a}^{u} ; P_{R e f, a}^{u} ; P_{v, b}^{u} ; P_{h, b}^{u} ; P_{R e f, b}^{u}$,

$\left\{P_{h}^{u}=\frac{P_{h, a}^{u}+P_{h, b}^{u}}{2 P_{R e f, a}^{u}}, P_{v}^{u}=\frac{P_{v, a}^{u}+P_{v, b}^{u}}{2 P_{R e f, b}^{u}}, P^{u}=\frac{P_{h}^{u}+P_{v}^{u}}{2}\right\}_{P=T, R}$

where $P$ stands for transmittance $T$ or reflectance $R$

Directional properties have followed a similar process. The angular correction was calibrated through averaging over 'positive' and 'negative' angles, which also corrects other systematic errors by using the reference values obtained. Separate measurements for p- and s-polarization have been performed to be able to calculate the reflectance and transmittance of natural unpolarized light at oblique incidence:

$T_{+\theta, p}^{u} ; T_{+\theta, s}^{u} ; T_{R e f, p}^{u} ; T_{R e f, s}^{u} ; T_{-\theta, p}^{u} ; T_{-\theta, s}^{u}$ for each angle of incidence $\theta$, and

$T_{\theta, p}^{u}=\frac{T_{+\theta, p}^{u}+T_{-\theta, p}^{u}}{2 T_{R e f, p}^{u}}, \quad T_{\theta, s}^{u}=\frac{T_{+\theta, s}^{u}+T_{-\theta, s}^{u}}{2 T_{R e f, s}^{u}} ; \quad T_{\theta}^{u}=\frac{T_{\theta, p}^{u}+T_{\theta, s}^{u}}{2}$.

$\left\{R_{+\theta, p}^{i} ; R_{+\theta, s}^{i} ; R_{R e f}^{i} ; R_{-\theta, p}^{i} ; R_{-\theta, s}^{i}\right\}_{i=u, m}$ for each angle of incidence $\theta$, and

$$
\begin{aligned}
\left\{R_{\theta, j}^{u}\right. & \left.=\frac{1}{2} \cdot\left[\frac{R_{+\theta, j}^{u} / R_{R e f}^{u}}{R_{+\theta, j}^{m} / R_{R e f}^{m}}+\frac{R_{-\theta, j}^{u} / R_{R e f}^{u}}{R_{-\theta, j}^{m} / R_{R e f}^{m}}\right] \cdot C R_{\theta, j}^{m}\right\}_{j=p, s} ; \\
R_{\theta}^{u} & =\frac{R_{\theta, p}^{u}+R_{\theta, s}^{u}}{2},
\end{aligned}
$$

where superscript $m$ is for "reference mirror" (reflectance measurements), $R_{\text {Ref }}^{i}$ correponds to $R_{+45^{\circ}, p}^{m}$ in each sequence, and $C R_{\theta, j}^{m}$ stands for the calibration data of the reference mirror.

The number of measures has been limited in each sample due to the number of them and the measuring time, not accumulating enough statistics to evaluate the random uncertainty component. As the object of this study is to get a comparison between PV modules and not absolute values of these properties, the hypothesis has been that all results are affected by the same statistical uncertainty.

Therefore, a lower limit for the uncertainty is given because of it is referred to the experimental equipment uncertainty reported in [11] (in the range $0.2-1 \%$ depending on the wavelength, angle of incidence and polarization). The main contributions to the systematic uncertainty are the calibration uncertainty (reference mirror uncertainty between $0.3 \%$ and $0.8 \%$ ) and the detector non-linearity (between $0.1 \%$ and $0.2 \%$ ). Other sources of systematic uncertainty are the abscissa uncertainty (wavelength) and the angle accuracy of the sample rotation stage, but these are negligible for most wavelengths of interest

\subsection{The optical characteristic parameters}

The methods of determining the luminous and solar characteristics of glazing in buildings, based on spectral reflectance and transmittance measurements, are detailed in different norms [4-6] as mentioned in Section 1. In this study, the European Norm EN 410:2011 about glass in building [5], has been considered as reference.

According to this document, the main parameters that characterize a glazing are the light transmittance and the solar factor, and there are other parameters that provide supplementary information.

The light transmittance $\tau_{\mathrm{V}}(\alpha)$, represents the fraction of the incident light coming from a D65 standard illuminant with similar spectrum to daylight that passes through the glass and is viewed by a standard photopic observer:

$\tau_{V}(\alpha)=\frac{\sum_{\lambda=380 \mathrm{~nm}}^{780 \mathrm{~nm}} D_{\lambda}^{D 65} T(\lambda, \alpha) V(\lambda) \Delta \lambda}{\sum_{\lambda=380 \mathrm{~nm}}^{780 \mathrm{~nm}} D_{\lambda}^{D 65} V(\lambda) \Delta \lambda}$, 
where $D_{\lambda}^{\mathrm{D} 65}$ is the relative spectral distribution of the illuminant $\mathrm{D} 65, V(\lambda)$ is the spectral luminous efficiency of a standard photopic observer [13] and $\alpha$ is the angle of incidence, usually not appearing if the parameter refers to normal incidence $(\alpha=0)$.

The total solar energy transmittance, usually known as solar factor or g-value, represents the total solar energy transmitted indoors through the glazing, both by direct transmission and by the indoor emission of part of the absorbed energy:

$$
\begin{aligned}
g(\alpha) & =\tau_{e}(\alpha)+q_{i}(\alpha)=\tau_{e}(\alpha)+\alpha_{e}(\alpha) \cdot \frac{h_{i}}{h_{i}+h_{e}} \\
& =\tau_{e}(\alpha)+\left(1-\tau_{e}(\alpha)-\rho_{e}(\alpha)\right) \cdot \frac{h_{i}}{h_{i}+h_{e}},
\end{aligned}
$$

$\tau_{e}(\alpha)=\frac{\sum_{\lambda=300 \mathrm{~nm}}^{2500 \mathrm{~nm}} S_{\lambda} T(\lambda, \alpha) \Delta \lambda}{\sum_{\lambda=300 \mathrm{~nm}}^{2500 \mathrm{~nm}} S_{\lambda} \Delta \lambda}$,

$\rho_{e}(\alpha)=\frac{\sum_{\lambda=300 \mathrm{~nm}}^{2500 \mathrm{~nm}} S_{\lambda} R(\lambda, \alpha) \Delta \lambda}{\sum_{\lambda=300 \mathrm{~nm}}^{2500 \mathrm{~nm}} S_{\lambda} \Delta \lambda}$,

where $\tau_{e}$ is the solar direct transmittance, which represents the fraction of the incident solar radiation that passes through the glass, $q_{i}$ is the secondary internal heat transfer factor, $h_{i}, h_{e}$ are, respectively, the internal and the external heat transfer coefficients of the sample surfaces, $\alpha_{e}(\alpha)$ is the solar direct absorptance, $\rho_{\mathrm{e}}(\alpha)$ is the solar direct reflectance, and $S_{\lambda}$ the standard AM1.0G relative spectral distribution of solar radiation for a 1.0 air mass [14]. It is worth noting that surface heat transfer coefficients $h_{i}, h_{e}$ depend mainly on the position of the glazing, the wind speed, and corresponding ambient and surface temperatures. For comparing purposes, the European norm establishes as boundary conditions: vertical position of glazing, for the outer surface, forced convection with a wind velocity of $4 \mathrm{~m} / \mathrm{s}$ and radiative exchange with the ambient temperature of $10^{\circ} \mathrm{C}\left(h_{e}=25.0 \mathrm{~W} / \mathrm{m}^{2} \mathrm{~K}\right)$; for the inner surface, natural convection allowing a small amount of forced convection (wind velocity lower than $0.3 \mathrm{~m} / \mathrm{s}$ ) and radiative exchange with the ambient temperature of $20^{\circ} \mathrm{C}\left(h_{i}=7.7 \mathrm{~W} / \mathrm{m}^{2} \mathrm{~K}\right)$. In the outside environment, other authors [15] suggest values of the coefficient $h_{e}$, for summer conditions, of $18 \mathrm{~W} / \mathrm{m}^{2} \mathrm{~K}$, giving rise to an increase in the heat transfer to the inside.

Other parameters of interest included in the European Norm EN 410:2011 considered in this study are the light reflectance $\rho_{V}(\alpha)$, the general color rendering index $R_{a}$, the shading coefficient $S C$, and the ultraviolet transmittance $\tau_{\text {UV }}$.

The light reflectance $\rho_{V}(\alpha)$ represents the fraction of the incident light, coming from D65 daylight standard illuminant, which is reflected by the glass and is viewed by a standard photopic observer:

$\rho_{V}(\alpha)=\frac{\sum_{\lambda=380 \mathrm{~nm}}^{780 \mathrm{~nm}} D_{\lambda}^{D 65} R(\lambda, \alpha) V(\lambda) \Delta \lambda}{\sum_{\lambda=380 \mathrm{~nm}}^{780 \mathrm{~nm}} D_{\lambda}^{D 65} V(\lambda) \Delta \lambda}$.

The general color rendering index $R_{a}$, stands for the optical spectrum reproduction through the glass, that is, the accuracy in the colors reproduction:

$R_{a}=\frac{1}{8} \sum_{i=1}^{8}\left\{100-4.6\left(\sum_{X=U, V, W}\left(X_{t, i}^{*}-X_{r, i}^{*}\right)^{2}\right)^{1 / 2}\right\}$,

where $\left\{\left(U_{t, i}^{*}, V_{t, i}^{*}, W_{t, i}^{*}\right)\right\}_{i=1}^{8}$ and $\left\{\left(U_{r, i}^{*}, V_{r, i}^{*}, W_{r, i}^{*}\right)\right\}_{i=1}^{8}$ are the CIE 1964 color space coordinates for the eight test colors illuminated with and without interposed glazing, respectively. Their explicit calculation is described in detail in Ref. [16].
The shading coefficient, $S C$, compares the $g$-value of the tested glass with that of a standard 3-4 mm clear float glass:

$S C(\alpha)=\frac{g(\alpha)}{0.87}$.

The ultraviolet transmittance of the glass, $\tau_{\mathrm{UV}}$, represents the fraction of a UV standard radiation, which relative spectral distribution is $U_{\lambda}$ [5], that passes through the glass:

$\tau_{\mathrm{UV}}(\alpha)=\frac{\sum_{\lambda=280 \mathrm{~nm}}^{380 \mathrm{~nm}} U_{\lambda} T(\lambda, \alpha) \Delta \lambda}{\sum_{\lambda=280 \mathrm{~nm}}^{380 \mathrm{~nm}} U_{\lambda} \Delta \lambda}$

Furthermore, other characteristics of the glazing, not included in the European Norm EN 410:2011, should be considered in order to fully characterize the glazing behavior One of them is the backside spectral reflectance of the element, which is related not only with the aesthetic appearance of the glass from inside, but also with the indoor illumination and possible glare. In the case of PV laminates this reflectance could be significant due to the metallic back contacts of the PV cells. To properly evaluate this aspect the backside light reflectance, defined as the fraction of the incident light from an indoor reference illuminant that is reflected and viewed by a standard photopic observer, has been proposed. As reference illuminants, the standards D65 (daylight standard illuminant) and F2 (conventional fluorescent standard illuminant) have been considered:

$\rho_{V, \text { Rear }}^{\text {D65 }}(\alpha)=\frac{\sum_{\lambda=380 \mathrm{~nm}}^{780 \mathrm{~nm}} D_{\lambda}^{\mathrm{D} 65} R_{\text {Rear }}(\lambda, \alpha) V(\lambda) \Delta \lambda}{\sum_{\lambda=380 \mathrm{~nm}}^{780 \mathrm{~nm}} D_{\lambda}^{\mathrm{D} 65} V(\lambda) \Delta \lambda}$

$\rho_{V, \text { Rear }}^{\mathrm{F} 2}(\alpha)=\frac{\sum_{\lambda=380 \mathrm{~nm}}^{780 \mathrm{~nm}} D_{\lambda}^{\mathrm{F} 2} R_{\text {Rear }}(\lambda, \alpha) V(\lambda) \Delta \lambda}{\sum_{\lambda=380 \mathrm{~nm}}^{780 \mathrm{~nm}} D_{\lambda}^{\mathrm{F} 2} V(\lambda) \Delta \lambda}$

Another parameter to consider, which is widely used by the glass industry, is the selectivity index, $S$ [17]. It is used to compare the light transmissivity with the total energy transmittance of a glass, being a good indicator of the glass capacity to transmit daylight without extra thermal load. A high selectivity coefficient indicates a favorable performance for solar control purposes.

$S(\alpha)=\frac{\tau_{V}(\alpha)}{g(\alpha)}$

\section{Results}

First, some of the spectral transmittance and reflectance curves are shown and analyzed for each sample, and then the optical characteristic parameters obtained are presented. The transparency value of each different sample was calculated by means of the normalized integral of the spectral distribution of the transmittance.

This value may not be exactly the same as the sample nominal transparency, as it happens with the semi-transparent amorphous silicon laminates (aSi_b: 0.4\%; aSi_a-10: 13.4\%; aSi_a-20: $20.2 \%$; aSi_a-30: 32.2\%; aSi_a-40: 41.8\%).

\subsection{Transmittance measurements}

Regarding the transmittance measurements, all PV samples show two different regions: the occupied by the PV cells and the transparent between them. Except in the cases in which the PV cells are semi-transparent ( $m c S i \_d$ and aSi_a-\# samples), the transmittance of the area occupied by the PV cells is negligible, resulting in opaque regions regardless of the considered PV cell technology and the structure of the laminate (Fig. 3). Thus, the transparency of these samples comes from the transmittance between cells. From a manufacturing point of view, for the PV laminates based on thinfilm technologies this spacing is possible thanks to removing part of 


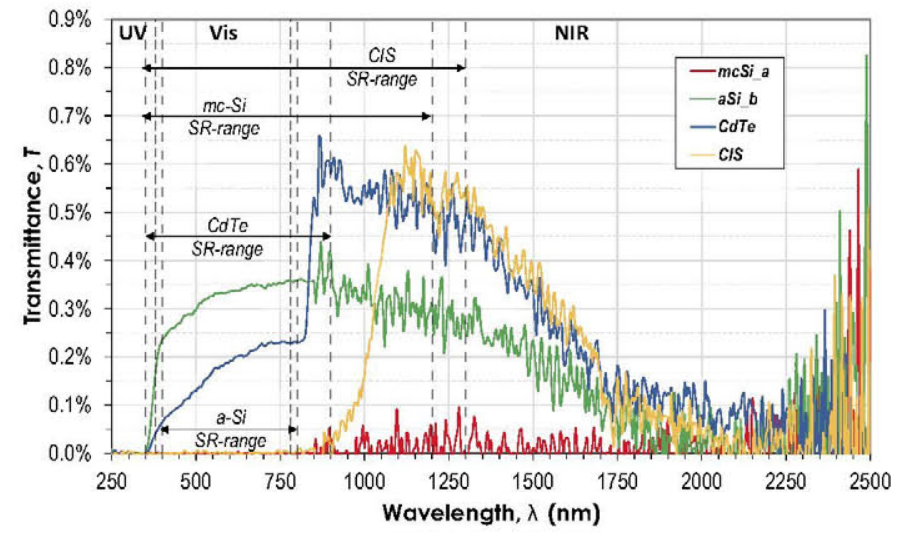

Fig. 3. Spectral transmittance of the opaque zone.

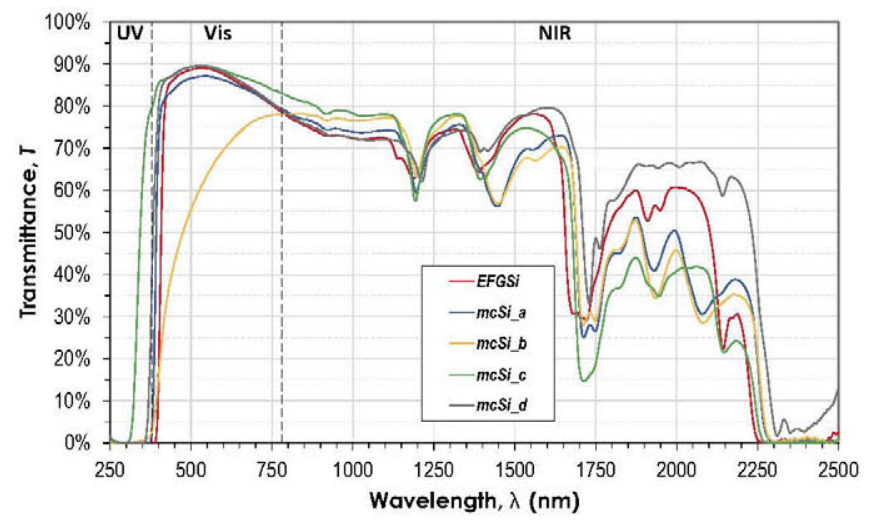

Fig. 4. Spectral transmittance of the transparent zone.

the PV active material and the use of transparent conductive oxides (TCO).

\subsubsection{Transmittance of the transparent part of the PV modules}

The transmittance of the transparent region qualitatively defines the transmission behavior of the entire PV module (Fig. 4). In the visible range, all the samples show high transmittance values with a maximum around $550 \mathrm{~nm}$, except the PV module with the aged encapsulant, whose lower light transmittance increases with wavelength. In the NIR range, laminates with EVA show higher transmittance values than laminates with PVB or resin, especially above $1750 \mathrm{~nm}$. In general, the spectral transmittance distribution of this region is similar to that of the conventional soda-lime silica laminated glass commonly used in the fenestration industry [18].

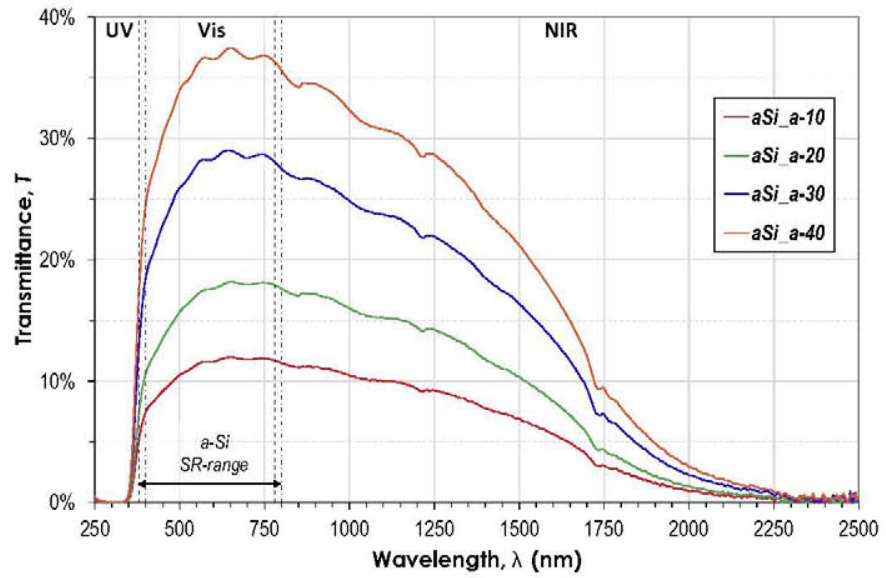

Fig. 6. Spectral hemispheric transmittance of the aSi_\# samples at normal incidence.

\subsubsection{Transmittance of the semi-transparent PV modules}

After separately characterizing the two types of regions of the crystalline silicon samples (transparent and opaque), the spectral transmittance is constructed by weighting the transmittance of each region. Fig. 5(a) and (b) compare the transmittances of two semi-transparent a-Si samples with those of crystalline silicon having the same transparency (10\% and $40 \%)$. The obtained transmittances are markedly different. Fig. 6 shows in detail the transmittance curves of all the semi-transparent amorphous silicon PV laminates, which grow gradually in the visible range reaching a maximum around $650 \mathrm{~nm}$, and decrease steadily throughout the NIR range.

The transmission curves show the daylight and solar modulating possibilities of the PV laminates. It is also clear the influence of the transparency in the loss of usable radiation for the PV conversion, as the transmission curves match the corresponding spectral response typical distributions.

\subsection{Reflectance measurements}

\subsubsection{Reflectance of the opaque part of the PV modules}

The spectral reflectance of the opaque region occupied by the PV cells significantly depends on the PV cell technology under study (Fig. 7). Nevertheless, all PV modules present low reflectance values for the wavelengths in the spectral response range of the corresponding technology, growing with the wavelength near the limits. This behavior is favorable to the PV conversion. EFG silicon (EFGSi sample) and CdTe (CdTe sample) technologies are those that reflect the greatest proportion of radiation in the NIR.
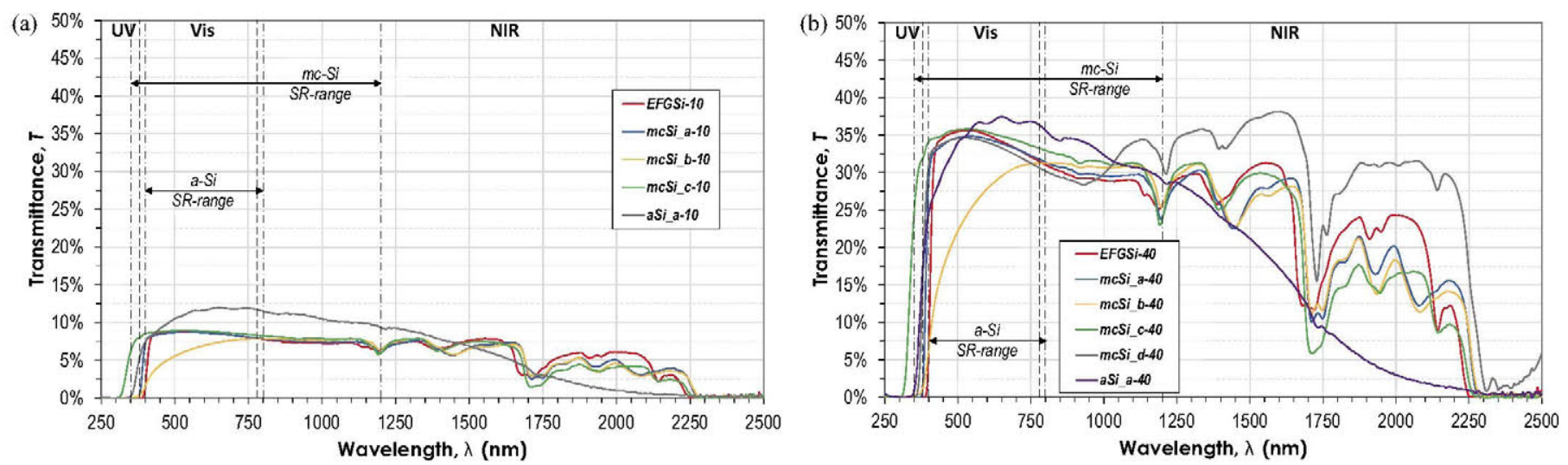

Fig. 5. Weighted spectral transmittances of the semi-transparent PV laminates ( $10 \%$ and $40 \%$ nominal transparency). 


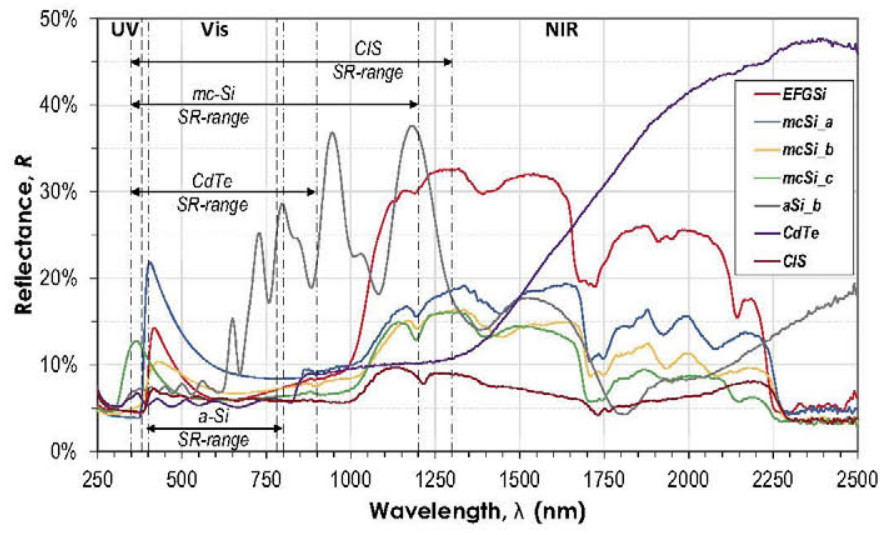

Fig. 7. Spectral hemispherical reflectance of the opaque zone.

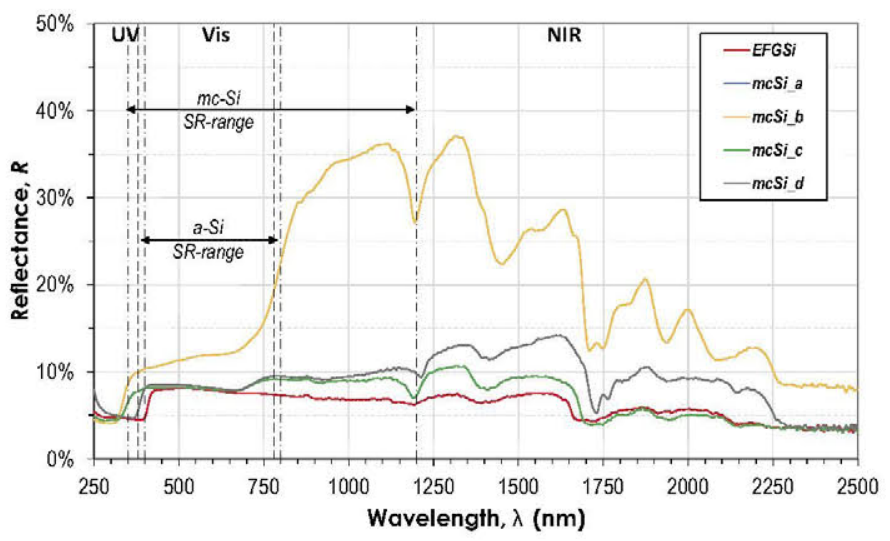

Fig. 8. Spectral hemispherical reflectance of the transparent zone.

\subsubsection{Reflectance of the transparent part of the PV modules}

The reflectance of the transparent areas is very similar to that of a soda-lime silica laminated glass [18] (Fig. 8). A value around $0.05-0.10$ was obtained in the entire range considered, except in the case of the aged PV module, which shows significantly higher reflectance. The different encapsulants are characterized by absorption peaks at certain wavelengths.

\subsubsection{Reflectance of semi-transparent PV modules}

The reflectance of the semi-transparent PV modules constructed by weighting the obtained spectral contribution of each different part, leads mainly to a scaled reflectance obtained from the opaque area performance (Section 3.2.1). Compared to the correspondent amorphous silicon PV samples (aSi_a-10 and aSi_a-40 samples), the

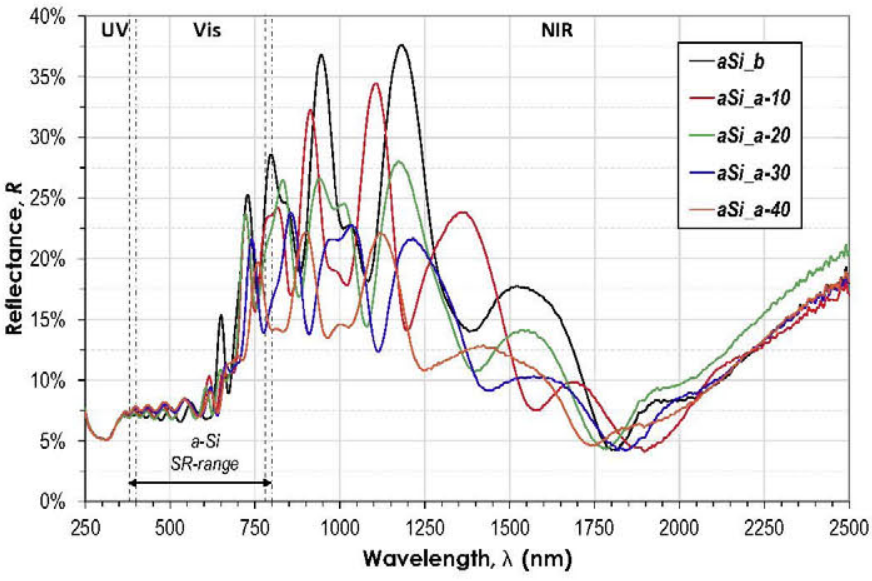

Fig. 10. Spectral hemispherical reflectance of the aSi_b and aSi_a-\# samples.

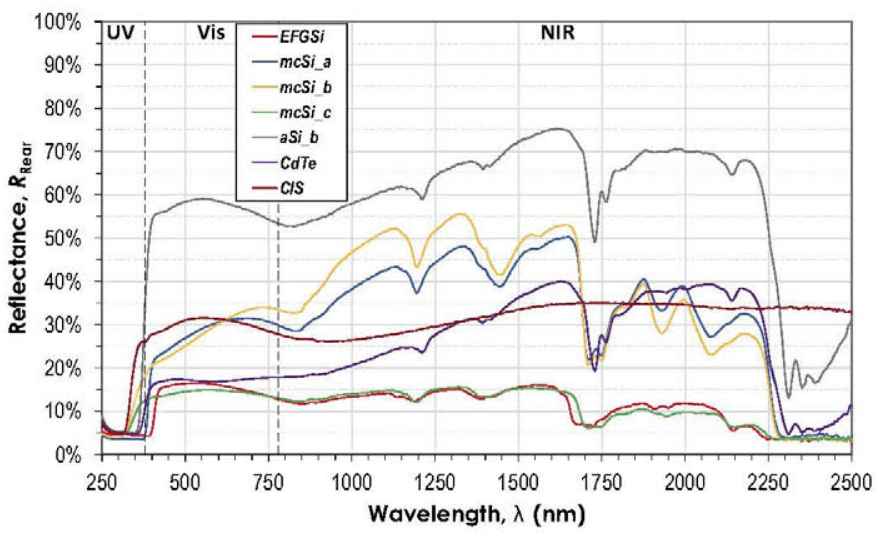

Fig. 11. Spectral reflectance of the opaque zone,

crystalline silicon ones reflect less in the range 600-1200 nm, which is positive for their PV conversion efficiency (Fig. 9(a) and (b)). On the other hand, the hemispherical reflectance results for aSi_a-\# samples (Fig. 10) show a limited influence of the transparency.

\subsubsection{Backside reflectance of the opaque part of the PV modules}

The back reflectance of the opaque area occupied by the PV cell is determined by the materials of the transparent layers of the rear face and, especially, of the PV cell back-contact. The first one imposes the profile of the spectral reflectance, and the second one determines the ratio of reflected radiation(Fig. 11). It is worth mentioning that in CIS PV modules the active material lies directly on
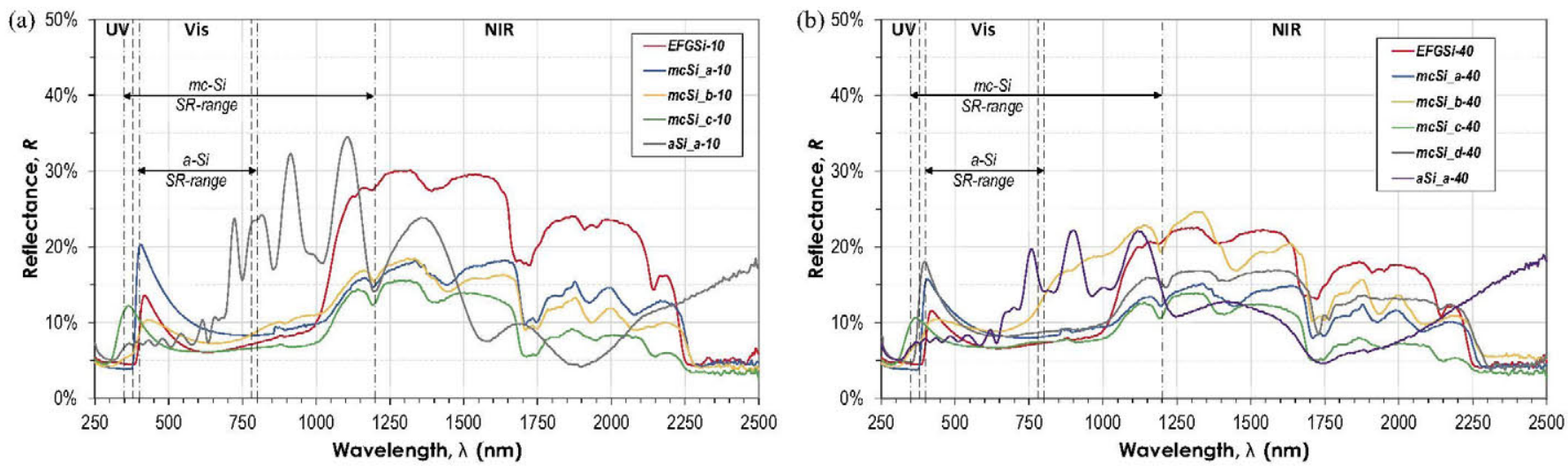

Fig. 9. Weighted spectral hemispherical reflectance of the semi-transparent PV laminates (10\% and 40\% nominal transparency). 

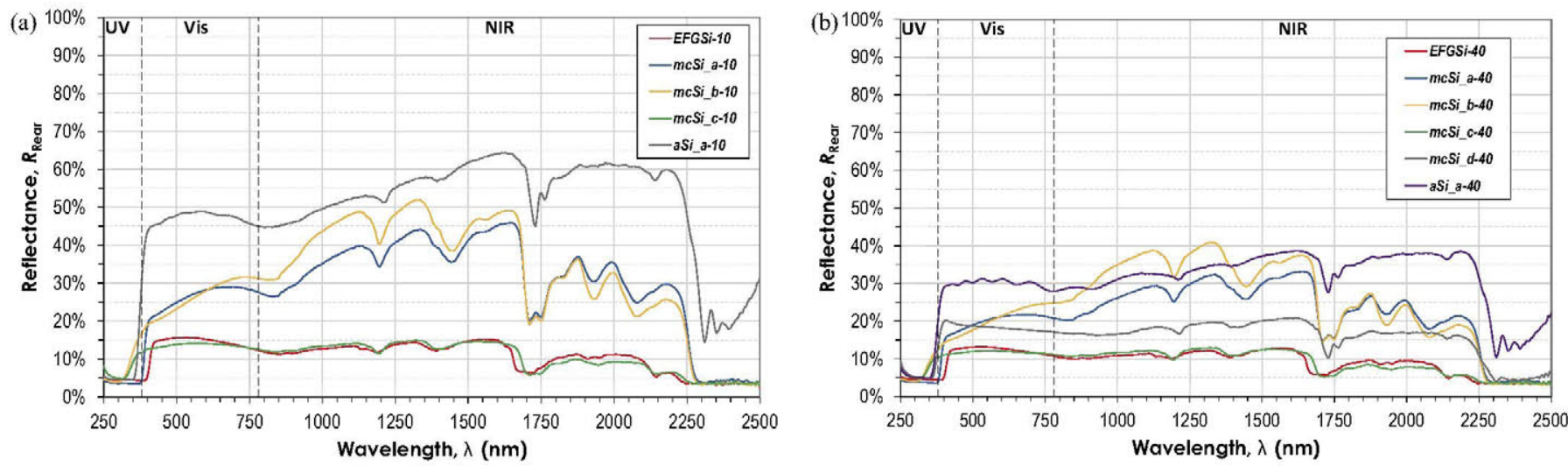

Fig. 12. Weighted spectral hemispherical reflectances of the non-active face of semi-transparent PV laminates ( $10 \%$ and $40 \%$ nominal transparency).

the inner side of the back glass, avoiding the rear encapsulant. That is the reason why their backside reflectance (CIS sample) doesn't show any absorption peaks, as do the rest of the measured PV modules.

\subsubsection{Backside reflectance of semi-transparent PV modules}

The backside reflectance of the semi-transparent PV laminates follows the pattern of the opaque area reflectance (Section 3.2.4), but reduced proportionally as the transparent surface increases (Fig. 12(a) and (b)). Reflectances of PV modules mcSi_a and $m c S i \_b$ are higher than that of other crystalline silicon samples (EFGSi and mcSi_c samples) due to the different back-contact material.

\subsection{Parameters obtained according to EN 410: 2011 and beyond}

\subsubsection{Characterization of the transparent part of the PV modules}

The obtained optical parameters from the transparent area of each PV laminate are shown in Table 2. The light transmittance is quite similar in all cases, around $0.88-0.89$, except in the case of the aged sample (mcSi_b), that is significantly lower, 0.64. Also this sample shows a lower solar factor than the rest, 0.66 against 0.80 , which leads to a shading coefficient of 0.76 , while the nonaged samples show higher values around $0.90-0.95$. Nevertheless, the color rendering index is high in all cases, 98.5\%.Apparently, UV transmission does not depend on the type of encapsulant. It is remarkable how high the UV transmittance of sample $m c-S i \_c$ is.

\subsubsection{Characterization of opaque PV modules and regions}

The luminous and solar characterization of opaque PV modules and of PV cell regions in semi-transparent PV laminates (Table 3) is based on the reflectance and the radiative re-emission $\left(q_{i} \mathrm{sec}-\right.$ ondary internal heat transfer factor) properties, since they present null transmittance. It should be noted that these opaque areas can absorb a large amount of radiation, avoiding the indoor direct transmission and thus leading to low g-values (around 0.21).

The light reflectance, mainly determined by the first glass interface, is low in all PV laminates because they are designed to maximize the efficiency of the PV modules, whose spectral responses match with the visible range in all cases. On the other hand, the backside light reflectance exhibits a high dependence with the PV technology, because it is mainly determined by the back-contact material. In thin-film PV modules ( $a$ Si_b and CIS samples), the presence of a metallic reflective film to enhance the confinement of photons, leads to higher reflectance values than in crystalline silicon PV solar cells.

\subsubsection{Standard characterization of the semi-transparent PV modules}

The standard optical parameters of the semi-transparent crystalline silicon PV modules, obtained from hemispherical measurements at normal incidence, are shown in Table 4 for assumed nominal transparencies of $10 \%$, and $40 \%$ one. Notice that the sample denoted as $m c S i$ d only includes values for $40 \%$ of transparency, as its PV cell has already an estimated transparency of $25 \%$. The results can be compared with those obtained with the semi-transparent aSi samples with similar transparency values, contained in Table 5. The light transmittance increases linearly with the PV laminate transparency, although not affecting the color rendering index. The $g$-value increases at a lower rate, despite the direct transmission increase, due to the decrease of the second order contribution to the g-factor (the indoor emission) with the transparency. As a consequence, the selectivity increases with transparency in all cases. The backside light reflectance is mainly determined by the back-contact type and the transparency of the sample.

Table 5 compares the obtained optical characteristics of the aSi PV laminates with those of three commercial PVB laminated glasses, denoted as CLST150, IPLUS and STADIP, the first two having low emission characteristics (low-E). The optical properties of these elements have been obtained from the respective datasheets (SGG COOL-LITE ST $1504 \mathrm{~mm}$ [19]; INTERPANE iplus sun $4 \mathrm{~mm}$ [17], SGG STADIP CLEAR $55.44 \mathrm{~mm}$ [19]) and from information provided by the software Window 6 (LBNL) and its related data base IGDB [20].

Observe that in the a-Si PV samples ( $a S_{-} b$ and $\left.a S_{-} a-\#\right)$ the obtained light transmittance characteristics and the solar factor (and consequently SC) depend linearly on the transparency of the samples, while the selectivity increases with the transparency following a concave quadratic dependence. Compared to the chosen commercial laminated glasses, the PV samples show less light transmittance but comparable light reflectance values from outside. The solar factors become also comparable at transparencies higher than $30 \%$. However, the backside light reflectance, which varies significantly with the transparency of the sample (from 0.59 to 0.31 ), is much higher than those of the commercial laminated glasses.

\subsubsection{The angle of incidence influence on the optical characteristics}

The a-Si semi-transparent PV samples (aSi_a-\#) have been considered for an optical characterization that takes into account the angle of incidence. Directional spectral transmittance and reflectance have been measured at different angles of incidence, from $0^{\circ}$ to $70^{\circ}$. Fig. 13(a) and (b) shows the results for the PV sample asi_a20. It can be observed that the reflectance curves shift 
Table 2

Luminous and solar characteristics of the transparent regions of the PV laminates.

\begin{tabular}{|c|c|c|c|c|c|}
\hline Sample ID & EFGSi & mcSi_a & $m c S i \_b$ & mcSi_c & mcSi_d \\
\hline \multicolumn{6}{|c|}{ Light characteristics } \\
\hline$\tau_{V}$ & 0.88 & 0.87 & 0.64 & 0.89 & 0.89 \\
\hline$R_{a}$ & $98.5 \%$ & $98.5 \%$ & $98.5 \%$ & $98.5 \%$ & $98.5 \%$ \\
\hline \multicolumn{6}{|c|}{ Solar characteristics } \\
\hline$\rho_{e}$ & 0.07 & 0.07 & 0.19 & 0.08 & 0.09 \\
\hline$\tau_{e}$ & 0.72 & 0.73 & 0.61 & 0.79 & 0.76 \\
\hline$\alpha_{e}$ & 0.21 & 0.19 & 0.20 & 0.13 & 0.15 \\
\hline$g$ & 0.77 & 0.78 & 0.66 & 0.80 & 0.80 \\
\hline SC & 0.89 & 0.90 & 0.76 & 0.90 & 0.92 \\
\hline$S$ & 1.1 & 1.1 & 1.0 & 1.1 & 1.1 \\
\hline$\tau_{\mathrm{UV}}$ & 0.00 & 0.00 & 0.01 & 0.55 & 0.06 \\
\hline
\end{tabular}

Table 3

Luminous and solar characteristics of the opaque PV modules and opaque regions of the semi-transparent PV laminates.

\begin{tabular}{|c|c|c|c|c|c|c|c|}
\hline \multirow[b]{2}{*}{ Sample ID } & \multicolumn{4}{|c|}{ Opaque modules } & \multicolumn{3}{|c|}{ Opaque regions } \\
\hline & $a S i b$ & CdTe & CIS & EFGSi & $m c S i \_a$ & $m c S i \_b$ & $m c S i \_c$ \\
\hline \multicolumn{8}{|c|}{ Light characteristics } \\
\hline$\rho_{V}$ & 0.08 & 0.06 & 0.06 & 0.07 & 0.11 & 0.08 & 0.06 \\
\hline$\rho_{V \text { Rear }}^{\mathrm{D} 65}$ & 0.59 & 0.17 & 0.31 & 0.16 & 0.29 & 0.28 & 0.15 \\
\hline $\begin{array}{l}\rho_{V, \text { Rear }}^{\text {Find }} \\
\text { Solar charad }\end{array}$ & 0.59 & 0.17 & 0.31 & 0.16 & 0.29 & 0.28 & 0.15 \\
\hline$\rho_{e}$ & 0.15 & 0.09 & 0.06 & 0.12 & 0.12 & 0.09 & 0.08 \\
\hline$\alpha_{e}$ & 0.85 & 0.91 & 0.94 & 0.88 & 0.88 & 0.91 & 0.92 \\
\hline$g$ & 0.20 & 0.22 & 0.22 & 0.21 & 0.21 & 0.21 & 0.22 \\
\hline
\end{tabular}

Table 4

Luminous and solar characteristics of the semi-transparent PV laminates with $10 \% / 40 \%$ nominal transparency.

\begin{tabular}{|c|c|c|c|c|c|}
\hline Sample ID & EFGSi & mcSi_a & $m c S i \_b$ & mcSi_c & mcSi_d \\
\hline $\begin{array}{l}\text { Transparency } \\
\text { Light characteristics }\end{array}$ & $10 \% / 40 \%$ & $10 \% / 40 \%$ & $10 \% / 40 \%$ & $10 \% / 40 \%$ & $40 \%$ \\
\hline$\rho_{V}$ & $0.07 / 0.07$ & $0.11 / 0.10$ & $0.08 / 0.09$ & $0.06 / 0.07$ & 0.09 \\
\hline$\tau_{V}$ & $0.09 / 0.35$ & $0.09 / 0.35$ & $0.06 / 0.26$ & $0.09 / 0.36$ & 0.23 \\
\hline$\rho_{V \text { Rear }}^{D 65}$ & $0.16 / 0.13$ & $0.27 / 0.20$ & $0.26 / 0.20$ & $0.14 / 0.12$ & 0.18 \\
\hline$\rho_{V \text { Rear }}^{\mathrm{F} 2}$ & $0.16 / 0.13$ & $0.27 / 0.21$ & $0.26 / 0.20$ & $0.14 / 0.12$ & 0.18 \\
\hline $\begin{array}{l}R_{a} \\
\text { Solar characteristics }\end{array}$ & $98.5 \% / 98.5 \%$ & $98.5 \% / 98.5 \%$ & $98.5 \% / 98.5 \%$ & $98.5 \% / 98.5 \%$ & $98.5 \%$ \\
\hline$\rho_{e}$ & $0.11 / 0.10$ & $0.11 / 0.10$ & $0.10 / 0.13$ & $0.08 / 0.08$ & 0.11 \\
\hline$\tau_{e}$ & $0.07 / 0.29$ & $0.07 / 0.29$ & $0.06 / 0.25$ & $0.08 / 0.32$ & 0.21 \\
\hline$\alpha_{e}$ & $0.82 / 0.61$ & $0.81 / 0.61$ & $0.84 / 0.63$ & $0.84 / 0.60$ & 0.68 \\
\hline$g$ & $0.26 / 0.43$ & $0.26 / 0.44$ & $0.26 / 0.39$ & $0.28 / 0.46$ & 0.37 \\
\hline$S C$ & $0.30 / 0.50$ & $0.30 / 0.50$ & $0.30 / 0.45$ & $0.32 / 0.53$ & 0.43 \\
\hline$S$ & $0.3 / 0.8$ & $0.3 / 0.8$ & $0.3 / 0.7$ & $0.3 / 0.8$ & 0.6 \\
\hline$\tau_{\mathrm{UV}}$ & $0.00 / 0.00$ & $0.00 / 0.00$ & $0.00 / 0.00$ & $0.06 / 0.22$ & 0.02 \\
\hline
\end{tabular}

to higher values as the angle of incidence increases, while transmittance curves shift to lower values. The reflection increase can be interpreted as angular losses for the PV conversion, already characterized and modeled for conventional PV modules [21-23].
Reflectance values above $25 \%$ were measured for the sample $a S i \_b$ at $70^{\circ}$ angle of incidence, which is a common operating condition in glazing in façades at medium latitudes. Similar results have been obtained for the rest of the samples.

Table 5

Luminous and solar characteristics of the amorphous silicon PV laminates and three different commercial glass laminates at normal incidence.

\begin{tabular}{|c|c|c|c|c|c|c|c|c|}
\hline Sample ID & $a S i b$ & $a S i \_a-10$ & aSi_a-20 & aSi_a-30 & aSi_a-40 & CLST150 & IPASOL & STADIP \\
\hline \multicolumn{9}{|c|}{ Light characteristics } \\
\hline$\rho_{V}$ & 0.08 & 0.08 & 0.08 & 0.08 & 0.08 & 0.19 & 0.16 & 0.08 \\
\hline$\tau_{V}$ & 0.00 & 0.11 & 0.17 & 0.28 & 0.36 & 0.46 & 0.48 & 0.87 \\
\hline$\rho_{V \text { Rear }}^{\text {D65 }}$ & 0.59 & 0.49 & 0.45 & 0.37 & 0.31 & 0.23 & 0.12 & 0.08 \\
\hline$\rho_{V, \operatorname{Rear}}^{\mathrm{F} 2}$ & 0.59 & 0.49 & 0.45 & 0.37 & 0.31 & - & - & - \\
\hline$R_{a}$ & - & $98.5 \%$ & $98.5 \%$ & $98.5 \%$ & $98.5 \%$ & - & - & - \\
\hline \multicolumn{9}{|c|}{ Solar Characteristics } \\
\hline$\rho_{e}$ & 0.15 & 0.14 & 0.14 & 0.13 & 0.11 & 0.19 & 0.32 & 0.07 \\
\hline$\tau_{e}$ & 0.00 & 0.10 & 0.15 & 0.23 & 0.30 & 0.38 & 0.22 & 0.68 \\
\hline$\alpha_{e}$ & 0.85 & 0.77 & 0.72 & 0.64 & 0.59 & 0.43 & 0.47 & 0.26 \\
\hline$g$-value & 0.20 & 0.28 & 0.31 & 0.38 & 0.44 & 0.47 & 0.26 & 0.76 \\
\hline$S C$ & 0.23 & 0.32 & 0.36 & 0.44 & 0.50 & 0.54 & 0.30 & 0.87 \\
\hline$S$ & - & 0.4 & 0.5 & 0.7 & 0.8 & 1.0 & 1.9 & 1.1 \\
\hline$\tau_{U V}$ & 0.00 & 0.01 & 0.02 & 0.04 & 0.05 & 0.27 & 0.08 & 0.00 \\
\hline
\end{tabular}


(a)

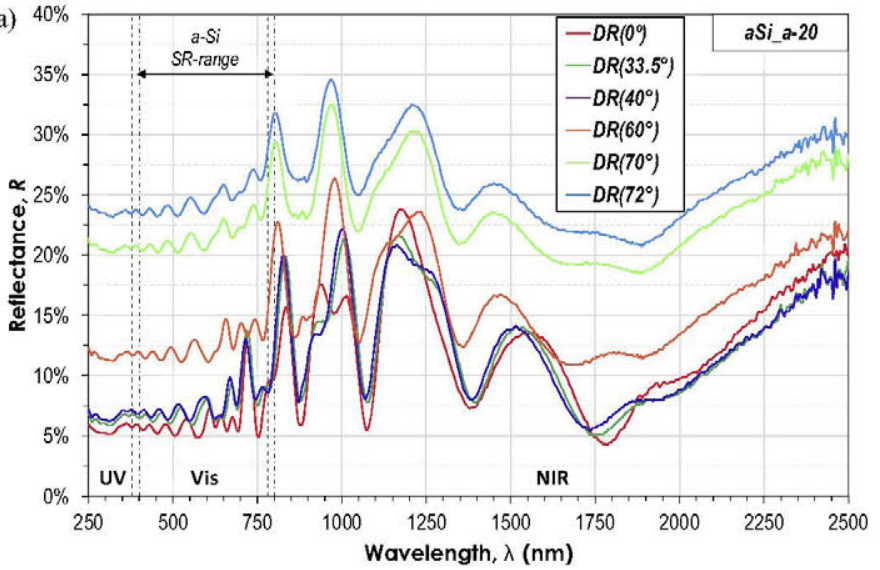

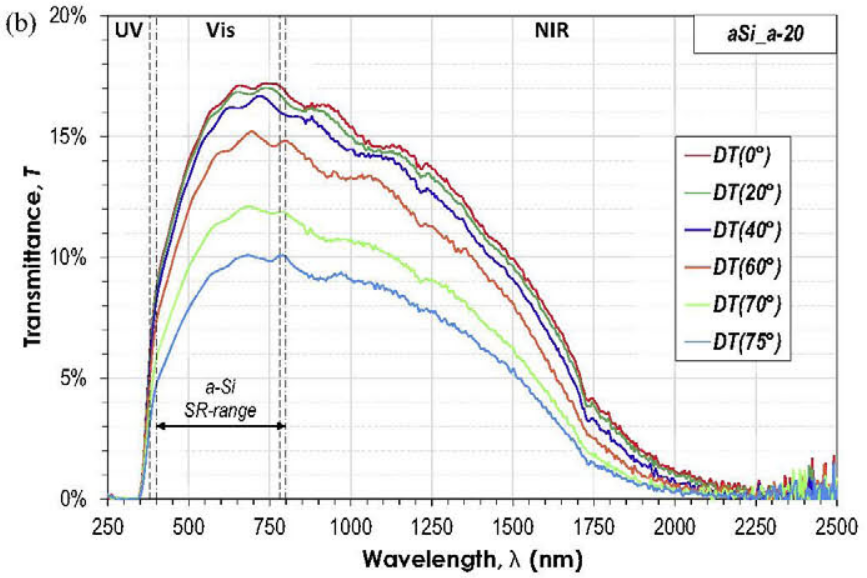

Fig. 13. Directional spectral reflectance (a) and transmittance (b) of the sample aSi_a-20, at different angles of incidence.

The light reflectance, which slightly depends on the transparency of the PV laminate, significantly increases with the angle of incidence, from an average value 0.06 at normal incidence to 0.21 at $70^{\circ}$, following a quasi-exponential type increase (Fig. 14). Results show that this dependence is mainly determined by the frontal glass, regardless of how much transparent the PV samples are.

Regarding the color rendering index, it is practically constant with the angle of incidence. Its value is $98.5 \%$.

However, the linear dependence of the solar factor with the transparency is function of the angle of incidence (Fig. 15): the bigger the angle, the weaker the linear dependence. This angle
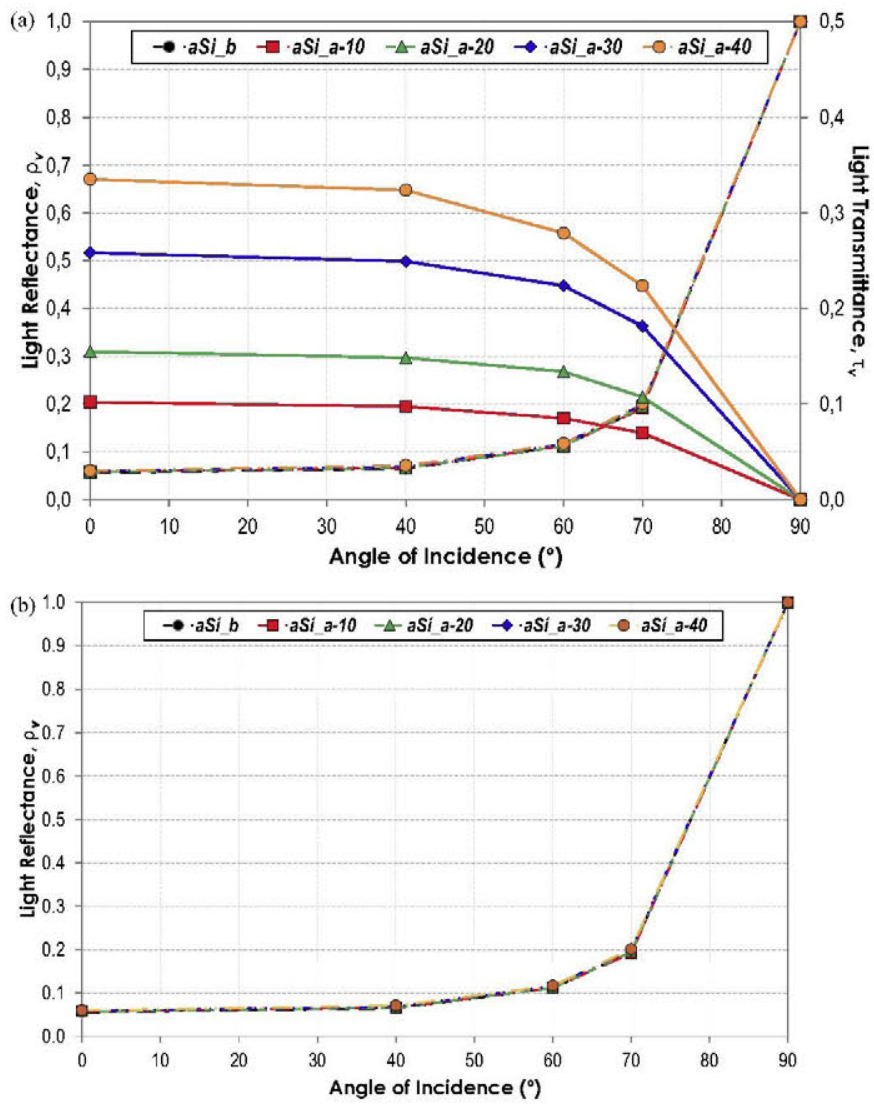

Fig. 14. Light reflectance and transmittance calculated from directional mea surements vs. the angle of incidence, for each different amorphous silicon semi-transparent PV laminate. dependence of the solar factor is shown in Fig. 16, which also includes the angle of incidence performance of the three commercial laminated glasses, for comparison.

Table 6 show the solar direct transmittance $\tau_{e}$ and the secondary internal heat transfer factor $q_{i}$ of the PV laminates and the three commercial laminated glass units at different angles of incidence. Some differences can be seen regarding these two terms of $g$-value. First, the PV laminates under study have lower solar direct transmittances than common laminated glasses, mainly due to the difference in transparency and the reduced reflectance of the PV modules in the optical range. On the other hand, the secondary internal heat transfer factor is in general higher in the PV laminates, although the most transparent sample (aSi_a-40) shows similar values of $q_{i}$ as CL_ST 150. Absorption in the opaque regions of the PV laminates is high, although part of it would be used for the PV conversion, thus reducing the indoor heat transmission. However, the $g$-values obtained are compatible with those reached using passive solar control systems.

Regarding the selectivity, the obtained values are in general lower than those of commercial glass units, due to the limited daylight transmission of the samples (also Table 6), which, in addition decreases with the angle of incidence. Nevertheless, again the most transparent sample shows similar values to CL_ST 150 .

The UV transmittance of the PV samples depends on the transparency, varying from 0 to 0.05 , but not as much on the angle of incidence. The UV transmittance should be considered in the PV

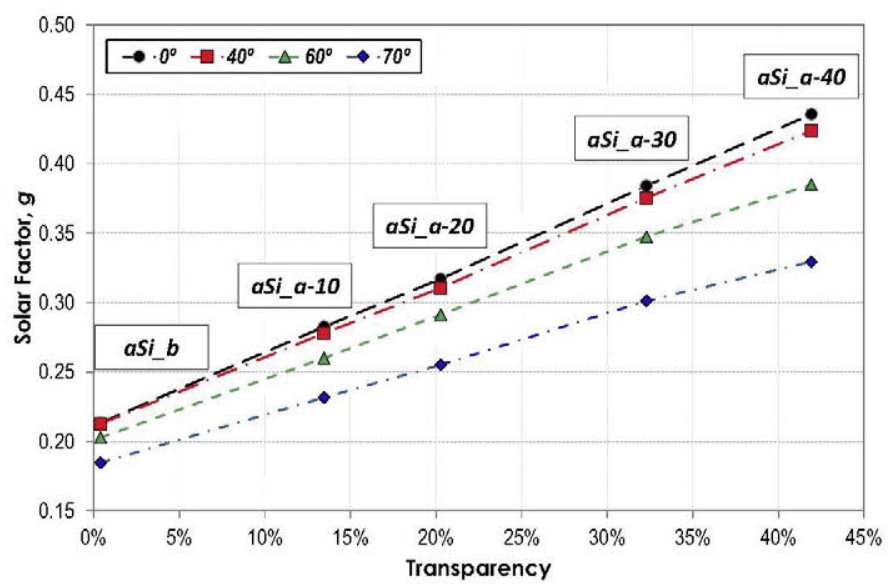

Fig. 15. Solar factor calculated from directional measurements vs. transparency, at different angles of incidence, for each different a-Si semi-transparent PV laminate. 
Table 6

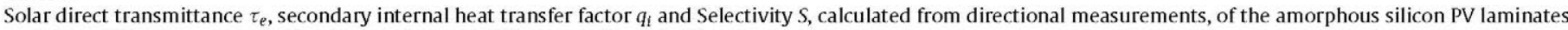
and three different commercial laminated glasses at different angles of incidence.

\begin{tabular}{|c|c|c|c|c|}
\hline & $0^{\circ}$ & $40^{\circ}$ & $60^{\circ}$ & $70^{\circ}$ \\
\hline aSi_a 10 & $0.09 / 0.19 / 0.4$ & $0.08 / 0.19 / 0.4$ & $0.07 / 0.18 / 0.3$ & $0.06 / 0.17 / 0.3$ \\
\hline aSi_a-20 & $0.14 / 0.18 / 0.5$ & $0.13 / 0.18 / 0.5$ & $0.12 / 0.17 / 0.5$ & $0.09 / 0.16 / 0.4$ \\
\hline aSi_a-30 & $0.22 / 0.16 / 0.7$ & $0.21 / 0.16 / 0.7$ & $0.19 / 0.16 / 0.7$ & $0.15 / 0.15 / 0.6$ \\
\hline asi_a-40 & $0.29 / 0.15 / 0.8$ & $0.27 / 0.15 / 0.8$ & $0.24 / 0.15 / 0.7$ & $0.19 / 0.14 / 0.7$ \\
\hline CL_ST 150 & $0.40 / 0.15 / 0.9$ & $0.39 / 0.15 / 0.9$ & $0.34 / 0.15 / 0.9$ & $0.28 / 0.15 / 0.8$ \\
\hline IPLUS & $0.38 / 0.07 / 1.7$ & $0.36 / 0.07 / 1.7$ & $0.32 / 0.07 / 1.7$ & $0.26 / 0.07 / 1.6$ \\
\hline STADIP & $0.68 / 0.08 / 1.1$ & $0.65 / 0.08 / 1.2$ & $0.59 / 0.09 / 1.2$ & $0.49 / 0.09 / 1.2$ \\
\hline
\end{tabular}
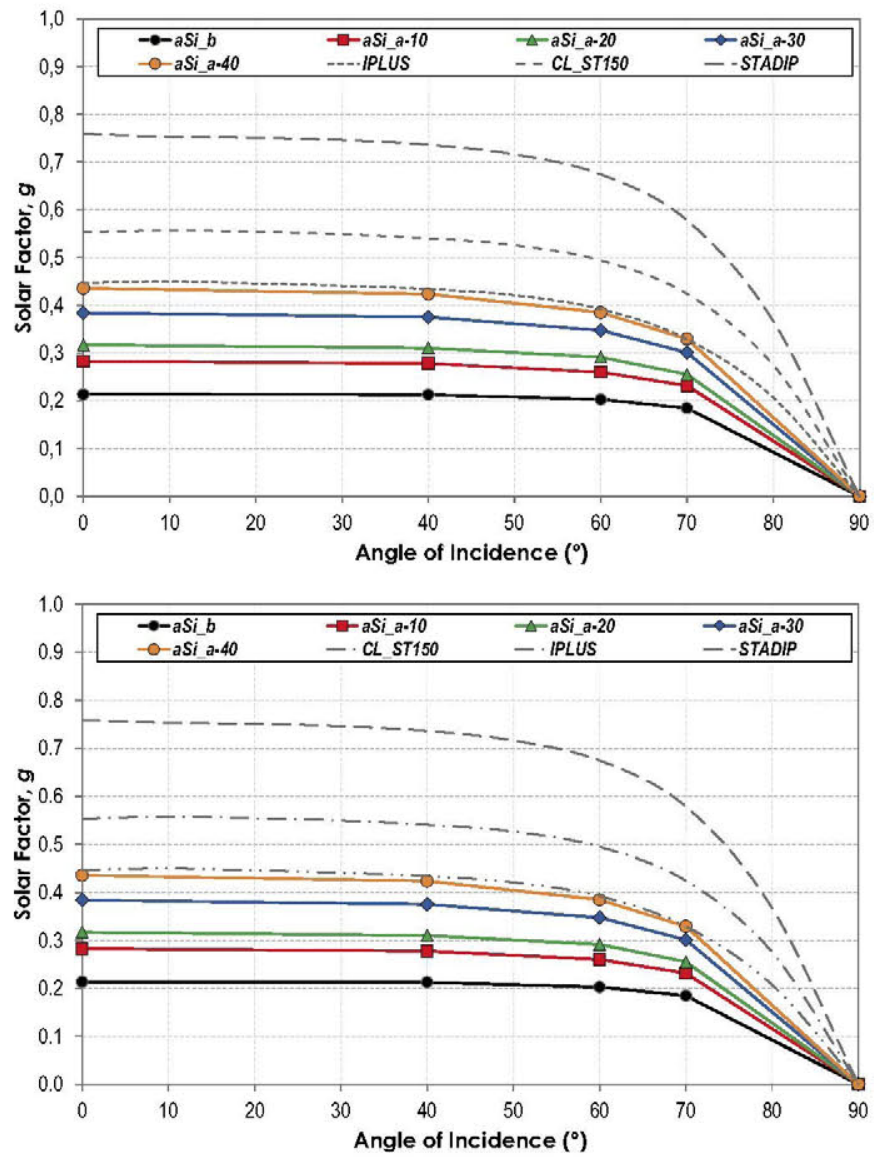

Fig. 16. Solar factor calculated from directional measurements vs. the angle of incidence, for each different a-Si semi-transparent PV laminate.

module design, although the values found in these samples do not differ too much from those of advanced solar control glazing.

\section{Conclusions}

A measurement campaign has been carried out with the goal of optically characterizing a representative set of PV laminates, based on different PV solar cell technologies, and suitable for building integration as multi-functional structural glasses. The European Norm EN 410:2011 developed to determine the luminous and the solar characteristics of glass in building, based on the measurement of UV/vis/NIR spectral reflectance and transmittance, has been considered. In addition, the influence of the angle of incidence on the characteristic parameters has also been measured and analyzed in the case of the semi-transparent PV laminates based on a-Si technology.

Three fundamental variables useful to assess the performance of the PV laminates as multifunctional building elements have been considered in this study: the PV module's technology and structure, the transparency degree and the angle of incidence of radiation.

The main luminous and solar characteristics, such as the light transmittance and the solar factor, are slightly dependent on the PV module technology and configuration but are very influenced by the transparency of the PV laminate, following a linear dependence. On the other hand, the front side light reflectance, which depends mainly on the first glass interface and is not affected by the transparency or the PV technology, keeps low in all cases, reducing the potential glare problems outside the building and favoring the PV conversion. Conversely, the reflectance of the non-active side of the PV module is clearly influenced by both the technology and the transparency, especially in the case of thin film technologies or other PV modules with high reflectance back metallic contacts, as mcSi_a and mcSi_b. It has also been observed that degradation of the encapsulant, which makes the laminate yellowing, results in loss of transmittance and increase of reflectance. In the studied case, this lead to $26 \%$ reduction of the light transmission and $11 \%$ reduction of the solar factor. Anyway, the good color rendering index observed in all cases (98.5\%) seems not to be affected by the encapsulant degradation.

Compared to standard PVB laminated glasses, PV modules show lower light transmittance and solar factor in all cases, although comparable $g$ values have been obtained for a transparency of $40 \%$ in amorphous and crystalline silicon PV laminates (around 0.4). In fact the study has demonstrated the daylight and solar modulating possibilities of the PV laminates by means of adjusting the transparency, with the advantage in the face of conventional laminates to convert part of the income irradiance into electrical power, improving the overall building energy balance.

According to the obtained results, it should be also noted the importance of considering the angular dependence of the properties in order to obtain more accurate and realistic evaluations of the solar systems performance. The angle of incidence starts to be significant from 60 degrees on and is more important in elements with higher transparency levels. The rate of change in the luminous and solar characteristics is higher in PV laminates than in conventional laminated glasses.

The final conclusion is that the results of this project indicate the good properties of PV laminated glasses in terms of daylighting and solar control capabilities allowing a feasible efficient integration in building façades of the PV generators. Besides, the obtained characteristic parameters can be used to simulate the influence in the energy balance of a building of different types of PV modules integrated in façade or window elements.

\section{Acknowledgements}

The authors are grateful to Dr. José-Lorenzo Balenzategui and Dr. Ricardo Enríquez (CIEMAT-DER, Madrid) for their valuable help to carry out this work. The authors are grateful to Soliker (Unisolar Group S.A.) for their support and for the supply of samples. This work has been partially supported by the Research Project OMEGACM S2013/MAE-2835 from the Autonomous Community of Madrid. 


\section{References}

[1] L. Olivieri, E. Caamaño-Martín, F.J. Moralejo-Vázquez, N. Martín-Chivelet, F. Olivieri, F.J. Neila-Gonzalez, Energy saving potential of semi-transparent photovoltaic elements for building integration, Energy 76 (2014) 572-583, http://dx.doi.org/10.1016/j.energy.2014.08.054

[2] European Parliament, Council of the European Union, Directive 2010/31/ EU of the European Parliament and of the Council of 19 May 2010 on the energy performance of buildings, Off. J. Eur. Union L153 (2010) 13-35.

[3] European Parliament, Council of the European Union, Directive 2012/ 27/EU of the European Parliament and of the Council of 25 October 2012 on energy efficiency, Off. J. Eur. Union L315 (2012) $1-56$.

[4] ISO, Glass in building. Determination of light transmittance, solar direct transmittance, total solar energy transmittance, ultraviolet transmittance and related glazing factors, in: ISO 9050:2003, ISO, 2003.

[5] EN, Glass in building. Determination of luminous and solar characteristics of glazing, in: EN 410:2011, EN, 2011.

[6] NFRC, Test Method for determining the solar optical properties of glazing materials and systems, in: NFRC 300:2014, NFRC, 2014.

[7] B. Petter, C. Breivik, H. Drolsum, Building integrated photovoltaic products: a state-of-the-art review and future research opportunities, Sol. Energy Mater. Sol. Cells 100 (2012) 69-96, http://dx.doi.org/10.1016/j.solmat.2011. 12.016

[8] I. Cerón, E. Caamaño-Martín, F.J. Neila, State-of-the-art of building integrated photovoltaic products, Renew. Energy 58 (2013) 127-133, http://dx.doi.org/ 10.1016/j.renene.2013.02.013

[9] PerkinElmer Inc., Brochure on "High Performance Lambda Spectroscopy Accessories", PerkinEImer Inc., 2010.

[10] PerkinElmer Inc., Application Note UV/vis/NIR on "Application and Use of Integrating Spheres with The LAMBDA 650 and 850 UV/Vis and LAMBDA 950 UV/vis/NIR Spectrophotometers”, PerkinElmer Inc., 2004
[11] P.A. Van Nijnatten, A spectrophotometer accessory for directional reflectance and transmittance of coated glazing, Sol. Energy 73 (3) (2002) 137-149, http://dx.doi.org/10.1016/S0038-092X(02)00047-6

[12] Perkin Elmer Inc., Lambda 800/900 User's Guide, Perkin Elmer Inc., 2003.

[13] CIE, Colorimetry, in: CIE 015:2004, 3rd Edition, 2004.

[14] CIE, Solar spectral irradiance, in: CIE 085:1989, CIE, 1989.

[15] F. Chen, S.K. Wittkopf, Summer condition thermal transmittance measurement of fenestration systems using calorimetric hot box, Energy Build. 53 (2012) 47-56, http://dx.doi.org/10.1016/j.enbuild.2012.07.005

[16] CIE, Method of measuring and specifying color rendering properties of light sources, in: CIE 013.3:1995, CIE, 1995.

[17] Interpane Glass Industrie AG, Interpane: Design with Glass, eighth ed., 2011, 〈http://www.interpane.com/design_with_glass_64.html [accessed 12.07.2014].

[18] D.C. Miller, M.D. Kempe, C.E. Kennedy, S.R. Kurtz, Analysis of transmitted optical spectrum enabling accelerated testing of multijunction concentrating photovoltaic designs, Opt. Eng. 50 (1) (2011) 013003-13011, http://dx.doi. org/10.1117/1.3530092

[19] Saint Gobain Glass, 2014. http://uk.saint-gobain-glass.com/products [accessed 17.11.2014].

[20] Lawrence Berkeley National Laboratory, Window 6.3 Software, 2011, http:/ windows.lbl.gov/software/window/window.html [accessed 17.11.2014]

[21] D.L. King, J.A. Kratochvil, W.E. Boyson, Measuring solar spectral and angle of incidence effects on photovoltaic modules and solar irradiance sensors, in: 26th IEEE PV Spec. Conf, 1997, pp. 1113-1116, http://dx.doi.org/10.1109/ PVSC.1997.654283

[22] N. Martín, J.M. Ruiz, Calculation of the PV modules angular losses under field conditions by means of an analytical model, Sol Energy Mater. Sol. Cells 70 (2001) 25-38, http://dx.doi.org/10.1016/S0927-0248(00)00408-6

[23] W. Hermann, L. Rimmelspacher, M. Reuter, Optical characteristic of PV module front glasses-incidence angle effects of various glass types and impact on annual energy yield, in: EU PVSEC, 2014, pp. 2882-2886, http://dx. doi.org/10.4229/28thEUPVSEC2013-4CO.11.5, vol. 2014. 